The reader must now imagine himself transported away up the Silk Road to a location in Central Asia which cannot be named or identified for security reasons, namely, the oilfield which to-day supplies the greater part of the petrol used by the Chinese. On the way, he will have passed for many miles along the Great Wall, and will have observed the triangulation tripods of the Chinese Geological Survey on some of the towers. At the oilfield, men from the Royal School of Mines (of South Kensington) are prominent; such as Dr. Shao I-Chou, who capably seconds Dr. Sun Yu-Chi as manager, and the oil geodesist, Dr. Ong Wên-Po. The field is one of the highest in the world, lying among the largely unexplored ranges of the Chilien Shan, and the issuing oil is probably the coldest, thus giving rise to special difficulties not met with elsewhere. The refinery, under the oil chemist, Dr. Chin Kai-Ying, produces all grades of petrol and light oils, waxes and greases. It seems clear that the field is a good deal larger than had hitherto been believed, and should be a highly important factor in post-war Chinese industrial prosperity. Nor does it stand alone, for seepages of oil occur all down through the Province of Kansu. They have been known to the peasants probably since remote antiquity, and have been used by them for greasing axles of country carts as well as medicinally; they account undoubtedly for mentions of oil by Marco Polo and for the accounts of "weak water" in other ancient and medieval writings.

Finally, the reader will remember that this region is one of the classical areas of the whole world for archæological exploration. The discoveries of Stein, von Lecoq and Hedin were possible largely because the desert climate preserves all sorts of antiquity in the most perfect way. One has only to dig in the rubbish-heap beside some deserted Han fort to find shards of Han basins, cloth belt of the Tang, a ropeend of the Sung, and broken pottery of all periods. So also the painted plaster surfaces of Lamaist stupatombs last in the open air surprisingly for centuries. Some fifteen miles south of Tunhuang, on the KansuSinkiang border, lies the historic site of Chienfotung ("Thousand-Buddha Caves"). Here, for a distance of some two miles along the dry river-bed, the metamorphosed gravel cliff is honeycombed with caves, ranging in size from a suitcase to a cathedral and partially protected from the weather by a small, well-irrigated, and charming oasis.

The walls and ceilings of the caves are covered with well-preserved fresco paintings of all periods from early Wei through Sui, Tang, and Sung to Yuan (A.D. 3801360), mostly of the earlier periods, illustrating the daily life of the people as well as the rites and ceremonies of the various forms of the Buddhist religion. They constitute, indeed, owing to the perishable nature of traditional Chinese architecture which used wood rather than stone, the greatest natural museum of art and archæology which China possesses. In one of these caves it was that Stein discovered long ago the famous hoard of Tibetan, Manichaean, Sogdian, Sanskrit, and Chinese books, much of which is to-day in the British Museum. In the oasis there is now a Tunhuang Research Station under the Ministry of Education; but unfortunately, in war-time, little has been done to preserve the caves, the painted plaster walls and statues in which do show a certain tendency to break away and spoil. It is a remarkable comment on Chinese traditions of scholarship, however, that in the middle of a war such as the present, their Central Press Agency should maintain at the caves a group engaged on a systematic photographic survey of the frescoes. This site will certainly in the future be the scene of further great discoveries of Chinese archæology.

${ }^{1}$ NATURE, 152, 9 (July 3,1943 ).

2 NATURe, 152, 36 (July 10, 1943).

3 NATURE, 152, 64 (July 17, 1943).

- NATURE, 152, 343 (Sept. 25, 1943)

5 NATURE, 152, 372 (Oct. 2, 1943).

\section{PHOTOGRAPHIC PHOTOMETRY}

A SYMPOSIUM on "Microdensitometry and A Microsensitometry" was held at the Royal Photographic Society's House in London on January 29. It was attended by members of the Royal Photographic Society and of the Association for Scientific Photography. There were four speakers : Dr. G. B. Harrison of the Research Laboratories of Ilford Limited ; Dr. A. Hunter of the Royal Observatory, Greenwich ; Mr. A. R. Stokes of the Crystallographic Laboratory, Cambridge ; and Mr. D. M. Smith of the British Non-Ferrous Metals Research Association. Dr. H. Baines, vice-president of the Royal Photographic Society, was in the chair.

After formal opening of the proceedings by the chairman, the subject was introduced by Dr. Harrison. He said that his task was to remind the audience of the more important factors which have to be borne in mind in accurate photographic photometry, particularly microphotometry. After pointing out that photographic materials, being sensitive to light, lend themselves to the comparison of light intensities, he said he wished to emphasize the fact that the use of photographic materials for such purposes is not without pitfalls for the unwary. Photographic photometry is based on the assumption that if two exposures are made on two different regions of the same photographic material, and these exposures are equal in all respects, then the densities produced by the two exposures will be equal. By exposure is meant the total amount of light received, which is the illumination multiplied by the time of exposure. It will be recognized that this assumption is only true under certain conditions, and a thorough knowledge of these limiting conditions is necessary to avoid the pitfalls and to pick one's way skilfully between them.

In practice, the magnitude of the test exposure to be measured will not be known, and it is necessary to record on the photographic material a range of exposures so that a curve relating some function of the exposure to the density produced can be drawn. It is in the application of this series of exposures that lies the key to accurate photographic photometry.

Dr. Harrison then reminded the audience of the requirements, which he said must not be regarded as placed in order of importance, because this depends on the conditions of the work in hand. The calibrating exposures should be similar in size, shape and surroundings to the test area. This arose because the density developed in any given area of material may be influenced by the density being developed in an adjacent area. The fact that the sensitivity varies with wave-length of radiation is so well known that it is obvious that the calibrating source should have the same spectral emission as the test source. Although the photographic material records the total amount of light, it is not indifferent to the way in which it is received. A high intensity for a short time does not give the same density as a low intensity for a long 
time, even though the total light received be the same. An exposure broken up into several shorter exposures may not give the same density as a continuous exposure of the same total light value. It is therefore necessary to ensure that the calibrating exposures have the same distribution in time as the test exposures, the intensity only being varied. The test and calibrating exposures should be separated by as short an interval of time as convenient, and if the interval has to be appreciable, a relatively long time should lapse before development. This precaution is occasioned by the possibility of changes in latent image after exposure and before development.

Having thus applied the calibration exposures, it is necessary to secure as uniform development as possible, and to measure all densities on the same densitometer. The particular type of densitometer used is of little importance provided it is capable of giving reproducible results.

Dr. Harrison said he had laid down briefly certain ideals to aim at, and he fully realized that it seemed a discouraging prospect, particularly as the practical conditions of the work frequently preclude the possibility of satisfying all the points enumerated. It is in these circumstances, however, that a full know. ledge of the limitations of the photographic process is so valuable in enabling the user to judge, or better still determine, the penalty he will have to pay, if any, for neglecting any of the fundamental requirements. In fact, the art of photographic photometry may be said to lie, not so much in the ability to satisfy all requirements, as in the ability to minimize the consequences of the inability to satisfy all.

Dr. Hunter then followed with an interesting paper on the use of microphotometry in astronomy. $\mathrm{He}$ said that photography is probably the astronomer's best friend because it is capable of recording total light and can integrate that light over long periods of time, and because it provides a permanent record. It is surprising how much useful information is obtained as a result of a re-examination of old plates in the light of new discoveries. The main use of photographic photometry is in the measurement of stellar magnitudes, and in the recording and measurement of stellar spectra. The latter give valuable information on temperature, and the Stark and Doppler effects yield data on mass and velocity respectively. The wave-length range concermed usually lies between 3,000 and 10,000A., though astronomers are generally rather suspicious of the behaviour of photographic materials at very long wave-lengths. To give some idea of the light intensities involved, he said that a first magnitude star provides an illumination of about one millionth of a metre-candle, and although the telescope might increase this by about a thousand-fold, it is still a very low level of illumination. When spectra are being recorded, it is, of course, lower still.

Referring to the requirements enumerated by Dr. Harrison, he said that frequently they cannot all be satisfied. For example, if the star image be formed on the slit of a spectrograph, the varying refraction of the atmosphere causes the image to move about, and in any event since the image is necessarily small, it is often artificially moved up and down the slit during the exposure to increase the effective height of the recorded spectrum. The exposure is therefore intermittent, though the calibrating exposure is normally continuous.

Perhaps a more flagrant breach of the conditions occurs when the calibrating exposure time differs from the test exposure time. Exposures are sometimes necessarily lengthy, and it is inconvenient to make the calibrating exposures of the same length. It is recognized that this procedure may lead to errors, and Dr. Hunter recalled an investigation he had made to determine the magnitude of the effect in relation to a series of experiments he was making. The calibrating exposures were made with an exposure time of $20 \mathrm{sec}$. and the test exposures varied from 20 sec. to more than 500 sec. The error was found to be appreciable and to vary with the type of plate used. He was able to obtain a relationship between observed and true stellar magnitude, so that a correction could be applied according to the test exposure time.

Dr. Hunter then discussed the question of the microdensitometer. He pointed out that most instruments give a record of the variation of transmission against position on the plate. What is really required is the curve of density against position, which can only be obtained by laboriously going over the transmission curve, taking the logarithm of the reciprocal of the transmission, and replotting. He showed diagrammatically the principle of a recording microdensitometer developed in Holland just before the War, which consisted in an addition to be fitted to any existing densitometer. The Dutch succeeded with this instrument in making a new atlas of the sun's spectrum which is already yielding valuable results. The chief drawback to this instrument is that a template has to be placed in part of the optical system of the subsidiary unit, and the shape of the template depends on the characteristics of the photographic material at the wave-length being measured.

In the United States a much more elaborate instrument has been built which overcomes this difficulty. The test spectrum and calibrating plate are both placed in position on the table of the instrument and the preparation of the density record is fully automatic. The instrument is said to be accurate, and a slide was shown of duplicate traces showing extremely good reproducibility.

The meeting was next addressed by Mr. Stokes, who commenced by briefly describing the fundamentals of X-ray crystallography with special reference to the Debye-Scherrer method. The specimen, consisting of a single (rocking) crystal or a 'powder', is placed at the centre of a circular camera carrying a strip of film located on the circumference of a circle with the specimen at the centre. A narrow pencil of $\mathrm{X}$-rays as nearly monochromatic as possible is incident on the specimen, and the emergent beam is trapped to avoid scattered radiation in the camera. The lines in the spectrum are reflected at different angles depending on the lattice structure of the crystal material and the wave-length of the incident radiation. The wave-length range with which the crystallographer is concerned is $0 \cdot 5-2 \cdot 5 \mathrm{~A}$. The width of the lines obtained depends on several factors, among which is the perfection of the crystal lattice itself. The line width is usually of the order $0.5 \mathrm{~mm}$. on the film.

With reference to the requirements laid down by Dr. Harrison, Mr. Stokes said that the crystallographer is probably in a privileged position in that the photographic material does not exhibit reciprocity failure when exposed to $\mathrm{X}$-rays. It is therefore possible to make the calibrating exposures by means of a time scale, for which a sector wheel giving exposures increasing in arithmetical progression is 
used. From density measurements on these regions a curve relating density to exposure can be drawn. This usually yields a straight line up to a density of about 1.5.

Mr. Stokes raised the important question of the effect of the size of the slit of the microdensitometer. The error introduced can be corrected by formula. In this connexion figures were given for the variation of observed density due to the graininess of the photographic material. The variations are appreciable, and it was pointed out that the height of the densitometer slit is limited by the fact that the spectral lines are curved, particularly at large angles of reflexion.

Another interesting point concerns the difference between the appearance of the X-ray spectrum and the recorded trace. A slide was shown illustrating a series of spectral lines and the corresponding density trace. The appearance of one of the lines suggested that there were two lines close together, one being much denser than the other. The densitometer trace revealed that the less dense 'line' was no more than a barely significant shoulder on the record of the line. The second peak was, in fact, not a peak at all, but merely an indication of the existence of a point of inflexion in the density trace. The slide showed the method of taking account of the fog or background which is nearly always present and usually increases towards the position -of zero deflexion of the ineident beam. It is usually possible on the density trace to draw a smooth line passing through the minimum density positions.

The use of photographic photometry in quantitative spectrum analysis was dealt with by Mr. Smith. The spark spectra of metals or alloys containing small quantities of impurities are recorded photographically, the most important region being in the ultraviolet from about $2,300 \mathrm{~A}$. to 4,500A. Spectrum analysis is most useful when the impurities are present in amounts less than about 2 per cent. The principle of the method is that the intensity of an impurity line is related to the intensity of a basis metal line according to the percentage impurity present. The procedure is to prepare a series of standards containing known quantities of impurity, and, by comparing the relative densities of basis metal and impurity lines, to determine the percentage corresponding with the relative densities obtained from the test sample.

Accurate calibration of the plate presents difficulties peculiar to the problem. Since a light source similar in constitution to the test source is required, a spark source is indicated; but unfortunately this is variable in both intensity and in the relative intensities of the different lines. The simplest and probably the most accurate method is to photograph a range of standards samples on each plate; but this has the disadvantage that it leaves less room for test exposures, it rapidly consumes carefully prepared and analysed standards and it appreciably increases the time taken. Another method is to use a rotating stepped sector in front of the slit. This method yields an intermittent calibrating exposure, but it has been claimed that this is permissible provided the sector disk is rotated at a rate of $200-300$ r.p.m. The intermittency effect can be overcome by using a stepped density wedge in place of the sector shutter, but this has been little used owing to the difficulty of obtaining satisfactory densities which are neutral over the requisite wave-length range.

Mr. Smith believes that the chief sources of error lie in the inconsistency of the light source, and that errors in the photographic process play a relatively unimportant part. He hopes that the reproducibility of the source will be improved in the near future.

Some discussion took place after the papers in which questions of detail were asked. Mr. L. V. Chilton agreed that photographic photometry has its difficulties and that a complete understanding of the principles involved is essential to success. On the other hand, microphotometry has its own particular difficulties, and though some of the speakers had indeed dealt with certain aspects, there are many interesting points peculiar to this field which could profitably be discussed in detail.

\section{THE FOREST AS A FACTORY}

\section{By Prof. E. P. STEBBING University of Edinburgh}

TN a memorandum written for a Government conference last summer, I made the statement that the forest is a "factory" just as much as a factory turning out tanks or aeroplanes. The statement appeared to create some surprise. Let us consider how it may be justified though, with the exception of India, inadequately recognized in that great organization the British Empire and Commonwealth of Nations.

We will first look at India; in spite of the fact that many heads of the other forest services hold that Indian forestry conditions, with all their great range of climate, soils, species, plains and mountains, are not applicable to conditions outside that country. During the War of 1914-18, India very soon found herself, owing to deficient shipping, deprived of many imported goods and left to her own resources. The forests, with an adequate forest staff for the purpose, were soon called upon to supply large military and civil requirements ; and the young Forest Research Institute played a remarkable part in assisting in this matter. This is familiar history. Once again, in the present War, the same position has had to be faced in India on an even larger scale. Once again her forests, having been under a conservative management for just eighty years, under an adequate forest staff and assisted by one of the biggest and best equipped forest research institutes in the world, have proved adequate to the call upon their resources.

An examination of some of the War publications from the latter, Records, Bulletins and Leaflets, prove, if proof be necessary, that the forest is merely a giant factory which in combination with the work of the research officer (for example, in an aircraft factory where the combination is now fully recognized) can face new demands, provided a sufficiency of labour is available. Examples of this work have already been given in these columns (NATURE, 153, 201 ; 1944). They furnish evidence of how research, with the forest to provide the necessary raw materials, was able to come to the assistance of the Fighting Services, as well as civilians, when imports of many kinds ceased. The research part of the 'factory' solved the problem of finding a substitute article for the one which could no longer be imported; the 'forest factory', according to location of supplies, well known to an organized department, provides the raw material ; and the third 'factory' in the business, the only one recognized by so many, makes up the article. But the third would have been non-existent 